\title{
PENGARUH KOMPENSASI, KEPEMIMPINAN, STIMULASI SOSIAL DAN KERJA SERTA KONDISI KERJA TERHADAP KEPUASAN KERJA KARYAWAN DI RUMAH SAKIT BAPTIS BATU
}

\author{
Sriwati \\ Fakultas Ekonomi Program Studi Manajemen \\ Universitas Riau Kepulauan
}

\begin{abstract}
This study aims to 1) analyze the effect of variable compensation, leadership style, social stimulation and work, and working conditions on employee job satisfaction at Baptist Hospital Batu and 2) to analyze which variables among these factors are the dominant influence on employee job satisfaction Baptist Hospital in Batu

The results showed that the variable compensation, leadership style, social stimulation and work, and working conditions have a significant effect on employee job satisfaction at Baptist Hospital Batu. So suitability salary with the duties and responsibilities, leadership style conformity with the will of employees, high social stimulation and employment and good working conditions will lead to increased job satisfaction of employees at Baptist Hospital Batu.

Compensation is an important variable dominant influence on employee job satisfaction at Baptist Hospital Batu, thereby achieving job satisfaction is determined more by the high compensation in the form of conformity salaries received by employees with job responsibilities, as well as the amount of salary received as compared with the type and responsibilities same responsibilities elsewhere.
\end{abstract}

Keywords:

Compensation, leadership, social stimulation and work, and working conditions, employee job satisfaction 


\section{PENDAHULUAN}

Dalam rangka optimalisasi sumber daya manusia, salah satu program yang perlu diperhatikan pada saat ini adalah dengan memenuhi kepuasan kerjanya. Dengan adanya pemenuhan kepuasan kerja, maka karyawan secara individual akan berusaha untuk meningkatkan kemampuannya. Sukses tidaknya suatu organisasi tergantung kepada kemampuan organisasi dalam memberikan kepuasan kerja terhadap karyawannya.

Demikian juga pada organisasi nirlaba seperti rumah sakit. Adanya persaingan antar rumah sakit yang semakin ketat, untuk itu peningkatan kualitas pelayanan sebuah rumah sakit sangat mutlak untuk diperhatikan. Persaingan yang terjadi bukan saja dari sisi teknologi pemeriksaan kesehatan dimana setiap rumah sakit memiliki alat-alat pemeriksaan dan penyembuhan yang relatif sama. Tetapi persaingan yang muncul dewasa ini adalah persaingan dalam hal pelayanan kesehatan yang berkualitas.

Perhatian terhadap kompensasi, kepemimpinan, stimulasi social dan kerja serta kondisi kerja tentunya sangat menunjang peranan rumah sakit yang selain merupakan organisasi yang bergerak di bidang pelayanan jasa kesehatan masyarakat juga memiliki unsur-unsur seperti halnya organisasi atau perusahaan pada umumnya. Artinya, rumah sakit juga harus berusaha untuk dapat memenuhi, merasakan, dan melayani setiap keinginan serta kebutuhan para pemakai jasa pelayanan rumah sakit tersebut, yaitu senantiasa memperhatikan setiap keluhan, pertanyaan ataupun opini yang datang dari para pemakai jasa rumah sakit tersebut. Sebab, masalah kesehatan yang bagi masyarakat merupakan suatu kebutuhan utama. Sehingga peranan rumah sakit yang dulunya hanya memberikan pelayanan yang bersifat penyembuhan belaka, tetapi saat ini berkembang kearah pelayanan yang menyeluruh dan terintegrasi. Hal tersebut mencakup upaya pencegahan dan peningkatan kesehatan yang serasi, yaitu kepada pelayanan kesehatan yang terbaik agar mampu memberikan kepuasan kepada para pasien yang menggunakan fasilitas jasa pelayanan di rumah sakit tersebut.

Berkait dengan berbagai hal yang telah dikemukakan di atas, penelitian ini akan ditekankan pada karyawan di Rumah Sakit Baptis Batu dimana rumah sakit ini mempunyai visi : "Menjadi Rumah Sakit Pilihan Utama Masyarakat Malang Raya karena pelayanan Kesehatan yang berpusat pada pasien dengan mengutamakan mutu dan keselamatan pasien",. Guna mencapai visi tersebut selain factor fasilitas yang lengkap, tidak kalah pentingnya adalah unsur sumber daya manusia di dalamnya, khususnya bagi karyawan yang bekerja di Rumah Sakit Baptis Batu. Karena karyawan dalam sebuah organisasi nir produksi seperti rumah sakit karyawan merupakan sumber daya utama dalam memberikan pelayanan bagi pengguna fasilitas jasa pelayanan rumah sakit, sehingga dituntut untuk dapat memberikan pelayanan yang maksimal kepada pasien. Dan dari jumlah karyawan Rumah Sakit Baptis Batu secara keseluruhan, yaitu sebanyak 350 karyawan, yang terdiri dari bagian perawatan, pelayanan, serta administrasi dianggap yang paling rentan terhadap ketidakpuasan kerja.

Berdasarkan hasil survey pendahuluan yang peneliti lakukan, didapatkan informasi beberapa orang karyawan secara umum merasakan belum adanya rasa keadilan (equity) terhadap gaji yang diterima sehubungan dengan pekerjaan yang dilakukannya meskipun gaji telah sesuai dengan UMR Kota Batu. Para karyawan menganggap kondisi kerja dilingkungan yang berdekatan dengan pasien serta penyakit yang dideritanya disekitar pekerja dinilai juga membahayakan para pekerja hal ini tentu saja dapat mempengaruhi dalam menjalankan tugas-tugas yang dibebankan.

Kepuasan gaji dapat diartikan bahwa seseorang akan terpuaskan dengan gajinya ketika persepsi terhadap gaji dan apa yang diperoleh sesuai dengan yang diharapkan. Hal secara tidak langsung akan dapat mengurangi kinerja maupun kepuasan karyawan dalam pekerjaannya akan memberikan pelayanan lebih baik dan bermutu kepada pasien rumah sakit sehingga kepuasan pasien dan keluarga pasien juga terpenuhi, yang pada akhirnya meningkatkan citra dan pendapatan rumah sakit (Crose, 1999), karena salah satu keberhasilan rumah sakit dalam meningkatkan mutu pelayanan kepada pasien memerlukan perawat yang merasa puas dalam pekerjaannya 
Berdasarkan fenomena tersebut, membawa dampak terganggunya pelayanan kepada pasien sebagai pengguna fasilitas jasa pelayanan Rumah Sakit Baptis Batu, dan dengan penjelasan di atas, maka peneliti tertarik untuk menganalisis lebih mendalam pada persoalan kepuasan kerja karyawan di Rumah Sakit Baptis Batu.

Tujuan penelitian ini adalah untuk Mendeskripsikan gambaran kompensasi, gaya kepemimpinan, stimulasi sosial dan kerja serta kondisi kerja dan kepuasan kerja karyawan di Rumah Sakit Baptis Batu, menganalisis pengaruh variabel kompensasi, gaya kepemimpinan, stimulasi sosial dan kerja, serta kondisi kerja terhadap kepuasan kerja karyawan di Rumah Sakit Baptis Batu dan Menganalisis variabel manakah di antara faktor-faktor tersebut yang berpengaruh dominan terhadap kepuasan kerja karyawan di Rumah Sakit Baptis Batu

\section{LANDASAN TEORI DAN HIPOTESIS}

\section{Kepuasan Kerja}

Menurut Handoko (2008:193-194) bahwa "kepuasan kerja (job satisfaction) adalah keadaan emosional yang menyenangkan atau tidak menyenangkan dengan mana para karyawan memandang pekerjaan mereka". Ini nampak dalam sikap positif karyawan terhadap pekerjaan dan segala sesuatu yang dihadapi di lingkungan kerjanya.

Menurut Spector (2007:3) bahwa faktor yang sering digunakan sebagai instrumen yang mempengaruhi kepuasan kerja adalah "appreciation, communication, coworkers, fringe benefits, job conditions, nature of the work, itself, organization itself, organization's policies and procedures, pay, personal growth, promotion opportunities, recognition, security, and supervision".

\section{Kompensasi}

Handoko (2008: 155) mengemukakan bahwa kompensasi adalah segala sesuatu yang diterima para karyawan sebagai balas jasa untuk kerja mereka. Menurut Simamora (2009: 540) kompensasi merupakan apa yang diterima oleh karyawan sebagai ganti kontribusi mereka kepada organisasi. Sedangkan menurut Nawawi (2009: 315) Kompensasi bagi organisasi merupakan penghargaan/ganjaran pendapatan pekerja yang telah memberikan kontribusi dalam mewujudkan tujuannya melalui kegiatan yang disebut bekerja.

Goodman dan Hullin dalam Shobaruddin (2002: 150-151) mengatakan bahwa kepuasan terhadap upah akan dipengaruhi oleh kebutuhan dan nilai-nilai pekerja. Jika upah pekerja cukup untuk memenuhi kebutuhan keluarga dan dirinya, ia akan lebih puas dibanding jika karyawan menerima upah lebih rendah dari yang diperlukan untuk memenuhi standar hidup yang memadai. Karena pendapatan seorang pekerja lambat laun meningkat, maka standar hidupnya meningkat dan barang-barang mewah menjadi kebutuhan nyata. Jadi semakin tinggi upah, mungkin sekali hanya mengakibatkan peningkatan upah sementara. Meskipun jika standar hidup yang menjadi aspirasi seorang pekerja tidak mengalami kenaikan, inflasi mungkin sekali mengikis kepuasannya dengan tingkat upah tertentu yang diberikan. Semakin pekerja tergantung pada gaji atau upahnya untuk memuaskan kebutuhan-kebutuhan hidupnya, maka kepuasan terhadap upahnya akan banyak dipengaruhi oleh biaya hidupnya.

\section{Kepemimpinan}

Menurut Winardi (2000:2): "Pemimpin adalah seorang yang karena kecakapan pribadinya dengan atau tanpa pengangkatan resmi dapat mempengaruhi kelompok yang dipimpinnya untuk mengarahkan upaya bersama ke arah pencapaian sasaran tertentu".

Lebih lanjut Pamuji (2005:132) menyatakan bahwa gaya kepemimpinan ini menunjukan bagaimana seorang pemimpin berperilaku agar karyawannya (kelompok yang dipimpinnya) menjalankan aktivitas sesuai dengan yang seharusnya. Gaya kepemimpinan dapat dibedakan menjadi tiga yakni gaya motivasi, 
gaya kekuasaan dan gaya pengawasan, sementara Ralp M Stogdill (1974:371) memisahkan gaya kepemimpinan menjadi tiga yakni otoriter, demokrasi, dan kendali bebas.

\section{Stimulasi Sosial}

Libet dan Lewinsohn (dalam Cartledge dan Milburn, 1995) mengemukakan Stimulasi sosial adalah sebagai rangsangan untuk meningkatkan kemampuan yang kompleks untuk menunjukkan perilaku yang baik dinilai secara positif atau negative oleh lingkungan, dan jika perilaku itu tidak baik akan diberikan punishment oleh lingkungan. Kelly (dalam Gimpel \& Merrel, 1998) mendefinisikan keterampilan sosial sebagai perilaku-perilaku yang dipelajari, yang digunakan oleh individu pada situasi-situasi interpersonal dalam lingkungan. Stimulasi sosial, baik secara langsung maupun tidak membantu pekerja untuk dapat menyesuaikan diri dengan standar harapan pada organisasi dalam norma-norma yang berlaku di sekelilingnya (Matson, dalam Gimpel \& Merrell, 1998).

Menurut Anoraga (1998:86), bahwa komunikasi antar sesama yang hangat secara horizontal maupun vertikal merupakan faktor penyumbang terhadap kepuasan kerja. Hubungan sosial yang ada diantara karyawan merupakan faktor yang cukup penting dalam menimbulkan kepuasan dan kegairahan kerja. Adanya ketegangan yang muncul dalam hubungan ini mudah sekali menimbulkan akibat yang kurang baik. Dalam hal ini faktor kepribadian seringkali menonjol yang merupakan faktor yang langsung tak langsung mempengaruhi keharmonisan dalam hubungan sosial antar karyawan, demikian juga latar belakang dan adat kebiasaan para karyawannya.

\section{Kondisi Kerja}

Kondisi kerja adalah segala sesuatu yang ada disekitar para pekerja yang dapat mempengaruhi dirinya dalam menjalankan tugas-tugas yang dibebankan (Nitisemito, 2002 : 183). Kondisi kerja adalah lingkungan yang kongkrit dan abstrak yang mengelilingi kerja seseorang. Kondisi kerja terdekat dimaksudkan adalah lingkungan kerja yang secara langsung dapat dirasakan oleh karyawan dalam hal ini adalah pekerja. Kondisi kerja terdekat sikap dan tindakan rekan kerja dan penyelia serta iklim yang mereka ciptakan. Simamora (2009: 542) menjelaskan bahwa kondisi pekerjaan terdiri atas :

1. Kebijakan-kebijakan yang sehat

2. Supervisi yang kompeten

3. Kerabat kerja yang menyenangkan

4. Lingkungan kerja yang nyaman

Menurut Agus Ahyari (2001) bahwa faktor-faktor yang mempengaruhi kondisi kerja adalah kegiatan pengaturan kerja yang mencakup pengendalian suara bising, pengaturan penerangan tempat kerja, pengaturan suhu udara, pelayanan kebutuhan karyawan, pengaturan penggunaan warna, pemeliharaan kebersihan ditempat kerja, dan penyediaan fasilitas-fasilitas yang dibutuhkan karyawan.

\section{Kerangka Konsep Penelitian}

Penelitian ini menganalisis secara kuantitatif dengan pendekatan deskriptif guna menjawab masalah tentang kausalitas antara variabel-variabel yang mempengaruhi kepuasan kerja karyawan, kerangka penelitian tersebut dapat digambarkan sebagai berikut:

Gambar 1

Kerangka Konseptual Penelitian 


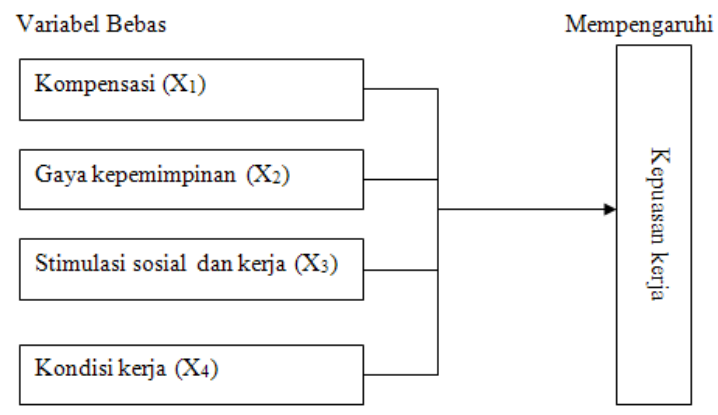

Pada gambar 1 dapat dijelaskan dalam sebuah organisasi seperti Rumah Sakit mempunyai karyawan maupun pekerja medis yang merupakan sumber daya utama dalam menjalankan operasinya, sehingga sebagai organisasi yang bergerak di bidang jasa pelayanan kesehatan ini memerlukan para anggota organisasi yang mempunyai kinerja yang tinggi agar dapat memaksimalkan pelayanan yang diberikan. Kinerja tinggi seperti yang diharapkan ini akan dapat terwujud jika unsur manusia yang bekerja di dalamnya merasa puas dalam bekerja.

Kepuasan kerja adalah istilah yang menunjukan sampai seberapa jauh organisasi memenuhi kebutuhan dan harapan para karyawannya. Kepuasan kerja dapat dipengaruhi oleh kehidupan individu yang bersangkutan, dapat memperbaiki sikap dan perilaku kerja, sehingga tujuan organisasi dapat tercapai secara maksimal. Salah satu cara agar kepuasan para karyawan dapat terpenuhi adalah dengan memperhatikan pemberian kompensasi berupa gaji berarti penghargaan/ganjaran kepada para pekerja yang telah memberikan kontribusi dalam mewujudkan tujuan rumah sakit. Kajian ini menunjukkan bahwa kepuasan kerja karyawan masih didasarkan pada kebutuhan fisik karyawan tersebut, hal ini mendukung penelitian yang dilakuan oleh Ernawati (2007) yang mengungkapkan gaji sebagai imbalan yang diberikan oleh rumah perusahaan dalam upaya meningkatkan kepuasan kerja perlu dipertimbangkan dalam mengkaji sumber daya manusia.

Hal lain yang berpengaruh dalam kepuasan adalah cara yang diterapkan pimpinan dapat mempengaruhi karyawan agar dapat bekerja lebih baik yang pada akhirnya dicapai kepuasan kerja pada diri karyawan. Hal di atas juga harus ditunjang dengan adanya stimulasi sosial dan kerja seperti yang diungkapkan Kuncoro (2001) yang mengungkap bahwa stimulasi sosial dan kerja merupakan pandangan karyawan terhadap hubungan sosial antar karyawan dan antara karyawan dengan pimpinan dimana Stimulasi kerja berupa kesempatan pengembangan karir dengan pemberian kesempatan pelatihan akan dapat meningkatkan kemampuan dan ketrampilan pada semua karyawan sesuai dengan bidang pekerjaannya.

Bagian terakhir dalam mencapai kepuasan kerja ini adalah perhatian terhadap Kondisi kerja, dimana kondisi kerja adalah segala sesuatu yang ada disekitar para pekerja yang dapat mempengaruhi dirinya dalam menjalankan tugas-tugas yang dibebankan. Dalam penelitian Yunus (2008) menjelaskan Kondisi kerja adalah lingkungan yang kongkrit dan abstrak yang mengelilingi kerja seseorang. Kondisi kerja terdekat dimaksudkan adalah lingkungan kerja yang secara langsung dapat dirasakan oleh karyawan dalam hal ini adalah pekerja hal ini dalam penelitian yang dilakukan terbukti berpengaruh terhadap kepuasan kerja.

\section{HIPOTESIS}

1. Diduga variabel kompensasi, gaya kepemimpinan, stimulasi sosial dan kerja, serta kondisi kerja berpengaruh signifikan terhadap kepuasan kerja karyawan Rumah Sakit Baptis Batu Malang.

2. Diduga variabel kompensasi merupakan faktor yang berpengaruh dominan terhadap kepuasan kerja karyawan Rumah Sakit Baptis Batu Malang 


\section{METODE PENELITIAN}

Penelitian ini menggunakan analisis kuantitatif dengan metode statistik deskriptif dan Multiple Linear Regresion. Adapun ruang lingkup penelitian ini difokuskan pada pengelolaan sumber daya manusia dengan menganalisis variabel-variabel yang mempengaruhi kepuasan kerja karyawan Rumah Sakit Baptis Batu, dengan demikian obyek penelitiannya adalah kepuasan kerja karyawan Rumah Sakit Baptis Batu.

Penelitian ini menetapkan lokasi pada Rumah Sakit Baptis Batu, yang terletak di Jalan Raya Tlekung No.I Kecamatan Batu, Kota Batu Jawa Timur, yang merupakan organisasi yang bergerak di bidang pelayanan jasa kesehatan (health care) dan Rumah Sakit Baptis Batu juga merupakan salah satu dari tiga rumah sakit swasta terbesar yang ada di Kota Batu propinsi Jawa Timur.

\section{Variabel Penelitian}

a. Variabel bebas (independent variable)

Variabel bebas adalah variabel yang keberadaannya tidak tergantung atau dipengaruhi oleh variabel lain. Dalam penelitian ini yang tergolong sebagai variabel bebas adalah kepuasan kerja yang meliputi :

1) kompensasi $\left(X_{1}\right)$

2) gaya kepemimpinan $\left(X_{2}\right)$

3) stimulasi sosial dan kerja $\left(X_{3}\right)$

4) kondisi kerja. $\left(\mathrm{X}_{4}\right)$

b. Variabel tergantung (dependent variable)

Variabel tergantung dalam penelitian ini adalah kepuasan kerja karyawan (Y).

\section{Instrumen Penelitian}

Instrumen yang dipakai sebagai alat untuk mengumpulkan data dalam penelitian ini adalah berupa daftar pertanyaan/ kuesioner jenis tertutup yang harus diisi oleh responden dengan cara mengisi dan memberi tanda tertentu pada alternatif jawaban yang dipilih. Kuesioner dimaksudkan untuk menjaring data yang berkaitan dengan variabel kepuasan kerja karyawan yang meliputi ; kompensasi, gaya kepemimpinan, stimulasi sosial dan kerja, serta kondisi kerja.

\section{Populasi dan Teknik Pengambilan Sampel}

Dalam penelitian ini populasinya adalah seluruh karyawan Rumah Sakit Baptis Batu dan terdaftar sebagai karyawan tetap. Jumlah karyawan secara keseluruhan adalah sebanyak 275 karyawan.

Penentuan jumlah sampel agar mewakili karakteristik populasi, maka diambil dari karyawan dengan penentuan besarnya sampel menggunakan metode Slovin dalam Umar (1999:108).

$$
\mathrm{n}=\frac{\mathrm{N}}{1+\mathrm{Ne}^{2}}
$$

Keterangan:

n: besarnya sampel.

$\mathrm{N}$ : besarnya populasi.

e: persen kelonggaran ketidaktelitian pengambilan sampel yang masih dapat ditolerir misalnya 10 $\%$.

Maka jumlah sampel yang diambil untuk penelitian ini sebanyak 73 orang.

Teknik pengambilan sampel yang digunakan adalah purposive sampling yaitu pengambilan sampel berdasarkan tujuan penelitian yang dilakukan. 


$$
\begin{aligned}
& \mathrm{n}=\frac{275}{1+\left(275 \times 0.1^{2}\right)} \\
& \mathrm{n}=\frac{275}{1+2.75} \\
& \mathrm{n}=73
\end{aligned}
$$

\section{Teknik Analisis Data}

Bertitik tolak dari rumusan masalah, tujuan penelitian dan jenis data yang akan dikumpulkan, maka analisis data dilakukan sebagai berikut :

1. Analisis Deskriptif

Analisis deskriptif untuk menjelaskan secara garis besar mengenai obyek penelitian dengan menggunakan distribusi frekuensi persentase serta nilai rata-rata variabel.

2. Analisis regresi berganda

Analisis regresi berganda dimaksudkan untuk menguji pengaruh secara simultan dan parsial antara kompensasi, gaya kepemimpinan, stimulasi sosial dan kerja, serta kondisi kerja dengan kepuasan kerja karyawan. Adapun persamaan regresi linier berganda adalah sebagai berikut :

$$
\mathrm{Y}=\mathrm{b}_{0}+\mathrm{b}_{1} \mathrm{X}_{1}+\mathrm{b}_{2} \mathrm{X}_{2}+\mathrm{b}_{3} \mathrm{X}_{3}+\mathrm{b}_{4} \mathrm{X}_{4}+\mathrm{e}
$$

\section{Dimana :}

$\begin{array}{ll}\mathrm{Y} & =\text { kepuasan kerja } \\ \mathrm{X}_{1} & =\text { kompensasi } \\ \mathrm{X}_{2} & =\text { gaya kepemimpinan } \\ \mathrm{X}_{3} & =\text { stimulasi sosial dan kerja } \\ \mathrm{X}_{4} & =\text { kondisi kerja } \\ \mathrm{b}_{0} & =\text { konstanta } \\ \mathrm{bi} & =\text { koefisien regresi } \\ \mathrm{e} & =\text { vaiabel pengganggu }\end{array}$

3. Uji asumsi klasik

4. Uji Hipotesis

a. Hipotesis I dengan uji F, yaitu menguji keberartian koefisien regresi (signifikansi) secara keseluruhan, dengan menggunakan rumus Cooper, (1999:125) sebagai berikut :

$\mathrm{F}=\frac{\mathrm{MSr}}{\mathrm{MSe}}$

Dimana :

$$
\begin{aligned}
& \mathrm{F} \quad=\text { Nilai } \mathrm{F}_{\text {hitung }} \\
& \mathrm{MSr} \quad=\text { rata-rata kuadrat regresi } \\
& \text { Mse } \quad \text { rata-rata kuadral error }
\end{aligned}
$$

$\mathrm{Ho}=\mathrm{B}_{1}=\mathrm{B}_{2}=\mathrm{B}_{3}=\mathrm{B}_{4}=0$

$\mathrm{Ha}=$ minimal satu koefisien $\mathrm{Bi} \neq 0$

Apabila hasil perhitungan menunjukan :

1) $F_{\text {hitung }}>F_{\text {tabel }}(\alpha=0,05)$, maka :

Ho ditolak

Ha diterima (signifikan)

Kaidah keputusan tolak Ho (terima $\mathrm{Ha}$ ) berarti variabel bebas mempunyai pengaruh yang bermakna terhadap variabel terikat (Y). 
2) $\mathrm{F}_{\text {hitung }} \leq \mathrm{F}_{\text {tabel }}(\alpha=0,05)$,

maka : Ho diterima

Ha ditolak

Variabel bebas (X) tidak ada pengaruh yang bermakna terhadap variabel terikat (Y).

Untuk mengetahui seberapa besar variabel bebas $(\mathrm{X})$ dapat menjelaskan perubahan variabel terikat ( $\mathrm{Y}$ ) digunakan nilai $\mathrm{R}^{2}$ (koefisien determinasi).

b. Hipotesis II

Untuk menguji hipotesis kedua terlebih dahulu diuji signifikansi masing-masing variabel menggunakan uji t dengan rumus (Cooper, 2005:124) sebagai berikut:

$\mathrm{t}=\frac{\mathrm{bi}}{\text { Sebi }}$

Dimana :

$\mathrm{t}=$ nilai $\mathrm{t}_{\text {hitung }}$

bi $=$ koefisien regresi

Se bi = standard error koefisien regresi

Rumusan hipotesis dinyatakan dengan :

$\mathrm{Ho}: \mathrm{Bi}=0$

$\mathrm{Ha}: \mathrm{Bi} \neq 0$

Apabila hasil perhitungannya menunjukan :

1) $t_{\text {hitung }}>t_{\text {tabel }}$ atau $t_{\text {hitung }}<-t_{\text {tabel }}$ pada taraf $\alpha=0,05$ maka Ho ditolak (Ha diterima) artinya variabel bebas secara parsial mempunyai pengaruh yang signifikan terhadap variabel terikat pada tingkat kepercayaan $95 \%$.

2) Apabila $-t_{\text {tabel }} \leq t_{\text {hitung }} \leq t_{\text {tabel }}$ pada taraf $\alpha=0,05$, maka Ho diterima (Ha ditolak) artinya variabel bebas secara parsial tidak mempunyai pengaruh yang signifikan terhadap variabel terikat pada tingkat kepercayaan $95 \%$.

\section{HASIL PENELITIAN DAN PEMBAHASAN}

\section{Hasil Uji Validitas dan Reliabilitas}

Hasil uji validitas

Validitas menunjukkan tingkat kemampuan instrumen penelitian, mengukur apa yang hendak diukur dan dapat mengungkapkan data dari variabel yang diteliti secara tepat. Uji validitas menggunakan teknik korelasi Product Moment dengan cara mengkorelasikan skor masing-masing item dengan skor total. Instrumen dinyatakan valid jika nilai korelasi Product Moment ( $r$ hitung) lebih besar dari nilai $r$ tabel pada taraf nyata $\alpha=5 \%$.

Tabel 2

Hasil Uji Validitas 


\begin{tabular}{|c|c|c|c|c|c|}
\hline Variabel & Item & $\begin{array}{c}\text { Nilai Korelasi } \\
\text { (I thang) }\end{array}$ & $\begin{array}{c}r \text { abel } \\
(\alpha=5 \%)\end{array}$ & Pengujian & Keterangan \\
\hline \multirow{6}{*}{$\mathrm{X}_{1}$} & $\mathrm{X}_{1.1 .1}$ & 0.653 & 0.227 & \multirow{6}{*}{$r_{\text {matag }}>r_{\text {rabel }}$} & Valid \\
\hline & $\mathrm{X}_{1.12}$ & 0.753 & 0.227 & & Valid \\
\hline & $\mathrm{X}_{121}$ & 0.829 & 0.227 & & Valid \\
\hline & $\mathrm{X}_{1222}$ & 0.644 & 0.227 & & Valid \\
\hline & $\mathrm{X}_{13.1}$ & 0.615 & 0.227 & & Valid \\
\hline & $\mathrm{X}_{1,3.2}$ & 0.763 & 0.227 & & Valid \\
\hline \multirow{6}{*}{$\mathrm{X}_{2}$} & $\mathrm{X}_{21.1}$ & 0.773 & 0.227 & \multirow{6}{*}{$r_{\text {matag }}>r_{\text {abeal }}$} & Valid \\
\hline & $\mathrm{X}_{21,2}$ & 0.709 & 0.227 & & Valid \\
\hline & $\mathrm{X}_{221}$ & 0.729 & 0.227 & & Valid \\
\hline & $\mathrm{X}_{222}$ & 0.669 & 0.227 & & Valid \\
\hline & $\mathrm{X}_{23.1}$ & 0.647 & 0.227 & & Valid \\
\hline & $\mathrm{X}_{23,2}$ & 0.786 & 0.227 & & Valid \\
\hline \multirow{6}{*}{$\mathrm{X}_{3}$} & $\mathrm{X}_{3.1 .1}$ & 0.675 & 0.227 & \multirow{6}{*}{$I_{\text {binas }}>I_{\text {abel }}$} & Valid \\
\hline & $\mathrm{X}_{3.12}$ & 0.782 & 0.227 & & Valid \\
\hline & $\mathrm{X}_{3.21}$ & 0.623 & 0.227 & & Valid \\
\hline & $\mathrm{X}_{3222}$ & 0.769 & 0.227 & & Valid \\
\hline & $\mathrm{X}_{3.3 .1}$ & 0.628 & 0.227 & & Valid \\
\hline & $\mathrm{X}_{3,32}$ & 0.626 & 0.227 & & Valid \\
\hline \multirow{6}{*}{$\mathrm{X}_{4}$} & $\mathrm{X}_{4.1 .1}$ & 0.607 & 0.227 & \multirow{6}{*}{$r_{\text {matosg }}>r_{\text {tabel }}$} & Valid \\
\hline & $\mathrm{X}_{4.12}$ & 0.886 & 0.227 & & Valid \\
\hline & $\mathrm{X}_{421}$ & 0.631 & 0.227 & & Valid \\
\hline & $\mathrm{X}_{4,22}$ & 0.741 & 0.227 & & Valid \\
\hline & $\mathrm{X}_{43.1}$ & 0.635 & 0.227 & & Valid \\
\hline & $\mathrm{X}_{43,2}$ & 0.359 & 0.227 & & Valid \\
\hline \multirow{6}{*}{$\mathrm{Y}$} & $Y_{1.1}$ & 0.707 & 0.227 & \multirow{6}{*}{$\mathrm{I}_{\text {binogg }}>\mathrm{I}_{\text {abel }}$} & Valid \\
\hline & $\mathrm{Y}_{12}$ & 0.678 & 0.227 & & Valid \\
\hline & $\mathrm{Y}_{21}$ & 0.856 & 0.227 & & Valid \\
\hline & $\mathrm{Y}_{22}$ & 0.629 & 0.227 & & Valid \\
\hline & $\mathrm{Y}_{3.1}$ & 0.785 & 0.227 & & Valid \\
\hline & $\mathrm{Y}_{32}$ & 0.856 & 0.227 & & Valid \\
\hline
\end{tabular}

Hasil uji validitas pada tabel 5 dapat diketahui bahwa semua skor item berkorelasi signifikan dengan total skor, ditunjukkan nilai $r_{\text {hitung }}>r_{\text {tabel }}$. Korelasi yang signifikan antara skor item dengan total skor menunjukkan bahwa item yang digunakan dapat mengukur variabel yang diteliti, sehingga seluruh item pertanyaan dinyatakan valid.

\section{Hasil Uji Reliabilitas}

Reliabilitas menunjukkan sejauh mana hasil pengukuran tetap konsisten bila dilakukan pengukuran dua kali atau lebih terhadap gejala yang sama. Dalam penelitian ini, uji reliabilitas dilakukan dengan menggunakan metode Alpha Cronbach. Adapun hasil uji reliabilitas disajikan pada tabel berikut:

Hasil Uji Reliabilitas Instrumen

\begin{tabular}{|c|c|}
\hline Variabel & Koefisien Alpha \\
\hline $\mathrm{X}_{1}$ & 0,805 \\
$\mathrm{X}_{2}$ & 0,715 \\
$\mathrm{X}_{3}$ & 0,774 \\
$\mathrm{X}_{4}$ & 0,709 \\
$\mathrm{Y}$ & 0,841 \\
\hline
\end{tabular}

Sumber: Data primer diolah (lampiran 6)

Pengujian reliabilitas instrumen dilakukan pada item-item pertanyaan yang memiliki validitas. Instrumen dinyatakan reliabel jika harga reliabilitas yang diperoleh paling tidak mencapai 0,6 (Nurgiyantoro, 2000:312). Hasil uji reliabilitas yang disajikan pada tabel 6 menunjukkan bahwa masing-masing nilai koefisien reliabilitas lebih besar dari 0,6 sehingga instrumen yang digunakan dinyatakan reliabel.

\section{Deskripsi Variabel Penelitian}

Rata-rata skor ketiga indikator yang digunakan untuk mengukur kompensasi sebesar 3,57 (dibulatkan skor 4) menunjukkan bahwa kompensasi berupa imbalan atau penghasilan kotor yang diterima karyawan dari hasil pekerjaannya selama satu bulan dapat digunakan untuk memenuhi kebutuhan hidup keluarga dan dirinya sendiri dikatagorikan baik. 
Rata-rata skor ketiga indikator yang digunakan untuk mengukur gaya kepemimpinan dapat diketahui bahwa dalam menjalankan manajemen rumah sakit sehari-hari pimpinan lebih banyak menggunakan gaya kepemimpinan demokratis. Jika dilihat dari rata-rata skor variabel gaya kepemimpinan sebesar 3,4 (dibulatkan skor 3) menunjukkan bahwa gaya kepemimpinan yang diterapkan dapat dikategorikan cukup baik.

Rata-rata skor ketiga indikator yang digunakan untuk mengukur stimulasi sosial dan kerja sebesar 3,26 (dibulatkan skor 3) menunjukkan bahwa stimulasi sosial dan kerja di rumah sakit dapat dikategorikan cukup.

Rata-rata skor ketiga indikator yang digunakan untuk mengukur kondisi kerja sebesar 3,37 (dibulatkan skor 3) menunjukkan bahwa kondisi kerja di RS. Baptis Batu cukup baik.

Rata-rata skor ketiga indikator yang digunakan untuk mengukur kepuasan kerja sebesar 2,42 (dibulatkan skor 2) menunjukkan bahwa kepuasan kerja karyawan di RS. Baptis Batu rendah.

\section{Hasil Uji Asumsi Klasik}

Hasil Uji Multikolinieritas

Tabel 3

Hasil Uji Multikolinieritas

\begin{tabular}{|c|c|c|}
\hline Variabel & VIF & Keterangan \\
\hline $\mathrm{X}_{1}$ & 1,195 & Non Multikolinieritas \\
$\mathrm{X}_{2}$ & 1,137 & Non Multikolinieritas \\
$\mathrm{X}_{3}$ & 1,311 & Non Multikolinieritas \\
$\mathrm{X}_{4}$ & 1,291 & Non Multikolinieritas \\
\hline
\end{tabular}

Menurut Santoso (2000:292) jika VIF lebih besar dari 5, maka variabel tersebut mempunyai persoalan multikolinieritas dengan variabel bebas yang lain. Jika dilihat pada tabel 3, keempat variabel bebas memiliki nilai VIF kurang dari 5, sehingga tidak ada persoalan atau tidak terjadi multikolinieritas dalam model regresi.

\section{Autokorelasi}

Hasil perhitungan Durbin Watson $(d)$ dibandingkan dengan nilai $d$ tabel pada $\alpha=0,05$. Tabel $d$ memiliki dua nilai yaitu nilai batas atas $\left(d_{u}\right)$ dan nilai batas bawah $\left(d_{l}\right)$ untuk berbagai nilai $\mathrm{n}$ dan $\mathrm{k}$.

Jika

$\mathrm{d}<\mathrm{d}_{\mathrm{L}}$ Terjadi autokorelasi positif

$\mathrm{d}>4-\mathrm{d}_{\mathrm{L}}$ Terjadi autokorelasi negatif

$\mathrm{d}_{\mathrm{U}}<\mathrm{d}<4-\mathrm{d}_{\mathrm{U}}$ Tidak terjadi autokorelasi

$\mathrm{d}_{\mathrm{L}} \leq \mathrm{d} \leq \mathrm{d}_{\mathrm{U}}$ atau $4-\mathrm{d}_{\mathrm{U}} \leq \mathrm{d} \leq 4-\mathrm{d}_{\mathrm{L}}$ Pengujian tidak meyakinkan 
Hasil uji Durbin Watson diperoleh nilai $d=1,822$ sedangkan pada $\alpha=0,05 ; \mathrm{k}=4$ diperoleh nilai $d u=$ 1,76 dan nilai 4- $d u=2,24$ jadi nilai $d$ berada di antara nilai $d u$ dan 4- $d u$ atau tidak terjadi autokorelasi.

\section{Heteroskedastisitas}

Hasil perhitungan korelasi Rank Spearman antara nilai residual dengan variabel bebas menunjukkan bahwa masing-masing variabel bebas tidak berkorelasi signifikan dengan residual di mana nilai signifikansi masing-masing variabel $>0,05$, hal ini menunjukkan bahwa residual konstan tidak dipengaruhi oleh perubahan variabel bebas, sehingga asumsi tidak adanya heteroskedastisitas dalam model regresi terpenuhi.

\section{Hasil Uji Hipotesis}

\section{Hasil uji hipotesis I}

Pengujian hipotesis I dengan Uji F (analysis of varian) digunakan untuk menguji apakah variabel kompensasi, gaya kepemimpinan, stimulasi sosial dan kerja, serta kondisi kerja berpengaruh signifikan terhadap kepuasan kerja karyawan, adapun hasil Analysis of Varian (ANOVA) dapat dilihat pada tabel 13 berikut:

Hasil Analysis of Varian (ANOVA)

\begin{tabular}{|c|c|c|c|c|c|c|}
\hline & Model & $\begin{array}{l}\text { Sum of } \\
\text { Squares }\end{array}$ & df & Mean Square & $\mathbf{F}$ & Sig. \\
\hline \multirow{3}{*}{1} & Regression & 10.102 & 4 & 2.525 & 37.412 & $.000^{\circ}$ \\
\hline & Residual & 4.590 & 68 & .068 & & \\
\hline & Total & 14.692 & 72 & & & \\
\hline \multicolumn{7}{|c|}{ a Predictors: (Constant), X4, X2, X1, X3 } \\
\hline \multicolumn{7}{|c|}{ b Dependent Variable: $Y$} \\
\hline \multicolumn{7}{|c|}{$R=0.829$} \\
\hline
\end{tabular}

Pada tingkat kepercayaan 95\% $(\alpha=5 \%)$ dan df $=4: 68$ diperoleh nilai $\mathrm{F}_{\text {tabel }}=2,503$ sedangkan nilai $F_{\text {hitung }}=37,412$ sehingga $F_{\text {hitung }}>F_{\text {tabel }}$ dan nilai signifikan 0,000 lebih kecil dari 0,05 jadi teruji bahwa kompensasi, gaya kepemimpinan, stimulasi sosial dan kerja, serta kondisi kerja berpengaruh signifikan terhadap kepuasan karyawan di RS. Baptis Batu, dengan demikian hipotesis pertama teruji.

Adapun kontribusi variabel kompensasi, gaya kepemimpinan, stimulasi sosial dan kerja, serta kondisi kerja terhadap kepuasan kerja karyawan dapat diketahui dari nilai koefisien determinasi $\left(\mathrm{R}^{2}\right)$ yaitu sebesar 0,688 menunjukkan bahwa variasi perubahan kepuasan kerja karyawan sebesar $68.8 \%$ disebabkan oleh kompensasi, gaya kepemimpinan, stimulasi sosial dan kerja, serta kondisi kerja, sedangkan sisanya sebesar $21.2 \%$ disebabkan oleh variabel lain yang tidak termasuk dalam penelitian seperti penghargaan, supervisi, prestasi kerja, dan budaya organisasi.

\section{Hasil Uji Hipotesis II}

Pengujian pengaruh masing-masing variabel bebas terhadap variabel terikat dapat disajikan pada tabel berikut: 


\section{Tabel Pengujian Regresi Secara Parsial}

\begin{tabular}{|c|c|c|c|c|}
\hline Model & $\begin{array}{c}\text { Beta } \\
(\beta)\end{array}$ & $\begin{array}{l}\text { Std. } \\
\text { Error }\end{array}$ & $\mathbf{t}$ & Sig. \\
\hline (Constant) & -3.232 & .464 & & \\
\hline Kompensasi (X1) & .381 & .079 & 5.148 & 0,000 \\
\hline Gaya kepemimpinan (X2) & .324 & .091 & 4.486 & 0,000 \\
\hline Stimulasi sosial dan kerja (X3) & .314 & .096 & 4.047 & 0,000 \\
\hline Kondisi kerja (X4) & .312 & .114 & 4.050 & 0,000 \\
\hline \multicolumn{5}{|l|}{ a Dependent Variable: Kepussan Kerja $(\mathrm{M})$} \\
\hline \multicolumn{5}{|l|}{ Persamasn Regresi: } \\
\hline \multicolumn{5}{|c|}{$\mathrm{Y}=-3,310+0,381 \mathrm{X}_{1}+0,324 \mathrm{X}_{2}+0,314 \mathrm{X}_{3}+0,312 \mathrm{X}_{4}$} \\
\hline
\end{tabular}

\section{1) Kompensasi $\left(X_{1}\right)$}

Hasil analisis regresi diperoleh nilai $t_{\text {hitung }}=5,148$ sedangkan nilai $t_{\text {tabel }}(\alpha=0,05 \mathrm{dan} \mathrm{df}=73)$ sebesar $=1,98$ sehingga $t_{\text {hitung }}>t_{\text {tabel }}$ dan nilai signifikansi sebesar 0,000 lebih kecil dari 0,05 berarti Ho ditolak (Ha diterima). Jadi teruji bahwa kompensasi berpengaruh signifikan terhadap kepuasan kerja karyawan di RS. Baptis Batu.

Koefisien regresi kompensasi $\left(b_{1}\right)$ sebesar 0,406 menunjukkan besarnya pengaruh kompensasi terhadap kepuasan kerja karyawan dengan pengaruh yang searah, artinya semakin tinggi kompensasi yang diterima karyawan berupa gaji, bonus dan tunjangan akan menyebabkan peningkatan kepuasan kerja karyawan dengan anggapan variabel lain konstan.

\section{2) Gaya Kepemimpinan $\left(X_{2}\right)$}

Hasil analisis regresi diperoleh nilai $\mathrm{t}_{\text {hitung }}=4,486$ sedangkan nilai $\mathrm{t}_{\text {tabel }}(\alpha=0,05 \mathrm{dan} \mathrm{df}=73)$ sebesar $=1,98$ sehingga $t_{\text {hitung }}>t_{\text {tabel }}$ dan nilai signifikansi sebesar 0,000 lebih kecil dari 0,05 berarti Ho ditolak (Ha diterima). Jadi teruji bahwa gaya kepemimpinan berpengaruh signifikan terhadap kepuasan kerja karyawan di RS.

Koefisien regresi gaya kepemimpinan $\left(\mathrm{b}_{2}\right)$ sebesar 0,408 menunjukkan besarnya pengaruh gaya kepemimpinan terhadap kepuasan kerja karyawan dengan pengaruh yang searah, artinya semakin baik gaya kepemimpinan akan menyebabkan peningkatan kepuasan kerja karyawan dengan anggapan variabel lain konstan.

\section{3) Stimulasi sosial dan kerja $\left(X_{3}\right)$}

Hasil analisis regresi diperoleh nilai $t_{\text {hitung }}=4,047$ sedangkan nilai $t_{\text {tabel }}(\alpha=0,05$ dan $\mathrm{df}=73)$ sebesar $=1,98$ sehingga $t_{\text {hitung }}>t_{\text {tabel }}$ dan nilai signifikansi sebesar 0,000 lebih kecil dari 0,05 berarti Ho ditolak (Ha diterima). Jadi teruji bahwa stimulasi sosial dan kerja berpengaruh signifikan terhadap kepuasan kerja karyawan di RS. Baptis Batu.

Koefisien regresi stimulasi sosial dan kerja $\left(b_{3}\right)$ sebesar 0,388 menunjukkan besarnya pengaruh stimulasi sosial dan kerja terhadap kepuasan kerja karyawan dengan pengaruh yang searah, artinya semakin baik stimulasi sosial dan kerja dalam wujud kerjasama, komunikasi dan kesempatan pengembangan karir akan menyebabkan peningkatan kepuasan kerja karyawan dengan anggapan variabel lain konstan.

\section{4) Kondisi kerja $\left(\mathrm{X}_{4}\right)$}

Hasil analisis regresi diperoleh nilai $t_{\text {hitung }}=4,050$ sedangkan nilai $t_{\text {tabel }}(\alpha=0,05 \mathrm{dan} \mathrm{df}=73)$ sebesar $=1,98$ sehingga $t_{\text {hitung }}>t_{\text {tabel }}$ dan nilai signifikansi sebesar 0,000 lebih kecil dari 0,05 berarti Ho ditolak (Ha diterima). Jadi teruji bahwa kondisi kerja berpengaruh signifikan terhadap kepuasan kerja karyawan di RS. Baptis Batu. 
Koefisien regresi kondisi kerja $\left(b_{4}\right)$ sebesar 0,460 menunjukkan besarnya pengaruh kondisi kerja terhadap kepuasan kerja karyawan dengan pengaruh yang searah, artinya semakin baik kondisi kerja berupa dukungan peralatan kerja, ruangan dan lingkungan kerja yang baik serta fasilitas yang mendukung akan menyebabkan peningkatan kepuasan kerja karyawan dengan anggapan variabel lain konstan.

Hasil uji regresi parsial menunjukkan bahwa keempat variabel bebas berpengaruh positif dan signifikan terhadap kepuasan kerja karyawan, selanjutnya untuk mengetahui variabel yang berpengaruh dominan terhadap kepuasan kerja adalah variabel yang paling signifikan (nilai $t_{\text {hitung }}$ paling besar) dan nilai koefisien regresi paling besar. Dari hasil analisis regresi pada tabel 15 di atas dapat diketahui bahwa kompensasi memiliki nilai t hitung paling besar yaitu 5,418 dan paling signifikan (nilai signifikansi < 0,05) jadi kompensasi merupakan variabel yang berpengaruh dominan terhadap kepuasan kerja.

Hasil uji hipotesis I menunjukkan bahwa secara umum model yang dipakai dapat digunakan untuk pengujian hipotesis yang menyatakan bahwa kompensasi, gaya kepemimpinan, stimulasi sosial dan kerja, serta kondisi kerja berpengaruh signifikan terhadap kepuasan kerja yang diukur dari kesenangan, kebanggan dan keamanan, ditunjukkan nilai $F_{\text {hitung }}>F_{\text {tabel }}$ pada tingkat kepercayaan $95 \%(\alpha=0,05)$. Kajian ini menunjukkan bahwa kesesuaian dalam kompensasi, gaya kepemimpinan yang sesuai dengan kemauan karyawan, stimulasi sosial dan kerja dalam wujud kerjasama dan kompensasi, serta kondisi kerja yang mendukung penyelesaian pekerjaan dapat menumbuhkan kepuasan kerja karyawan di RS. Baptis Batu.

Pada uji hipotesis II teruji terdapat pengaruh yang signifikan kompensasi $\left(\mathrm{X}_{1}\right)$ terhadap kepuasan kerja karyawan di RS. Baptis Batu. Kompensasi merupakan variabel yang paling dominan mempengaruhi kepuasan kerja karyawan RS. Baptis Batu masih berpegang pada seberapa besar imbalan yang akan diterima, sehingga karyawan akan selalu mengukur imbalan tersebut dengan kontribusi kerja yang akan diberikan kepada rumah sakit, dengan kata lain karyawan mempertimbangkan kesesuaian gaji yang diterima karyawan dengan tanggung jawab pekerjaan, serta besarnya gaji yang diterima dibandingkan dengan jenis dan tanggung jawab yang sama di tempat lain. Temuan ini sejalan dengan hasil penelitian Ernawati (2007) bahwa faktor finansial mempunyai pengaruh yang dominan terhadap kepuasan kerja. Tingginya skor variabel kompensasi (rata-rata 4) menunjukkan bahwa gaji yang diterima karyawan telah sesuai dengan tanggung jawab terhadap pekerjaan dan gaji yang diterima lebih baik dibandingkan dengan di tempat lain. Sejalan dengan pendapat Nawawi (2009:315) bahwa kompensasi berupa gaji berarti penghargaan/ganjaran kepada para pekerja yang telah memberikan kontribusi dalam mewujudkan tujuan rumah sakit. Kajian ini menunjukkan bahwa kepuasan kerja karyawan masih didasarkan pada kebutuhan fisik karyawan tersebut, dengan demikian terungkap bahwa gaji sebagai imbalan yang diberikan oleh rumah sakit dalam upaya meningkatkan kepuasan kerja perlu dipertimbangkan dalam mengkaji sumber daya manusia. Selain itu tingginya kompensasi juga didukung dari pemberian bonus dan tunjangan kepada karyawan, dimana bonus yang diberikan cukup memadai dengan prestasi kerja yang dicapai karyawan dan diberikannya tunjangan berupa tunjangan kesehatan, tunjangan hari raya, dan perumahan kepada karyawan. Kepuasan terhadap upah akan dipengaruhi oleh kebutuhan dan nilai-nilai pekerja. Jika upah pekerja cukup untuk memenuhi kebutuhan keluarga dan dirinya, ia akan lebih puas dibandingkan jika ia menerima upah lebih rendah dari yang diperlukan untuk memenuhi standar hidup yang memadai. (Goodman dan Hullin dalam Shobaruddin (2002:150-151). 


\section{KESIMPULAN}

1. Hasil jawaban responden menunjukkan skor variabel kompensasi (rata-rata 4) menunjukkan bahwa gaji yang diterima karyawan telah sesuai dengan tanggung jawab terhadap pekerjaan dan gaji yang diterima lebih baik dibandingkan dengan di tempat lain. Penerapan gaya kepemimpinan dinilai cukup baik oleh karyawan (rata-rata skor 3), dimana pimpinan dalam menjalankan aktivitasnya menerapkan kombinasi ketiga jenis gaya kepemimpinan yaitu gaya otoriter, gaya demokratis, dan gaya kendali bebas. Hasil penelitian dapat diketahui bahwa stimulasi sosial dan kerja dalam bentuk kerjasama, komunikasi dan pengembangan karir berjalan cukup baik (rata-rata skor 3), dan kondisi kerja yang merupakan keadaan atau kondisi dimana karyawan melaksanakan kegiatan kerjanya, dimana kondisi kerja di RS. Baptis Batu dapat dikatakan cukup baik (rata-rata skor 3).

2. Variabel kompensasi, gaya kepemimpinan, stimulasi sosial dan kerja, serta kondisi kerja berpengaruh signifikan terhadap kepuasan kerja karyawan di Rumah Sakit Baptis Batu. Jadi kesesuaian gaji dengan tugas dan tanggung jawab, kesesuaian gaya kepemimpinan dengan kehendak karyawan, tingginya stimulasi sosial dan kerja serta kondisi kerja yang baik akan menyebabkan peningkatan kepuasan kerja kerja karyawan di Rumah Sakit Baptis Batu.

3. Kompensasi merupakan merupakan variabel yang berpengaruh dominan terhadap kepuasan kerja karyawan di Rumah Sakit Baptis Batu, dengan demikian tercapainya kepuasan kerja lebih banyak ditentukan oleh tingginya kompensasi dalam bentuk kesesuaian gaji yang diterima karyawan dengan tanggung jawab pekerjaan, serta besarnya gaji yang diterima dibandingkan dengan jenis dan tanggung jawab yang sama di tempat lain.

\section{DAFTAR PUSTAKA}

Adiarni, Nunuk. (Trans). Gibson, Ivancevich, Donelly. 2006. Organisasi Perilaku, Struktur dan Proses. Edisi Kedelapan. Jilid Satu. Binarupa Aksara. Jakarta.

Anoraga, Pandji. 2003. Psikologi Kerja. Cetakan Kedua. Penerbit Rineka Cipta. Jakarta.

As’ad, Mohammad. 2001. Psikologi Industri. Edisi Keempat. Penerbit Liberty. Yogyakarta.

Azwar, Syaifuddin. 2008. Metodologi Penelitian. Edisi Pertama. Cetakan Pertama. Pustaka Pelajar Offset. Yogyakarta.

Cooper. 2002. BussinessResearch Methods. Home Wood. USA : Richard D. Irwin. Inc.

Dessler, Gary. 2007. Improving Productivity at Work. Reston Virginia. Reston Publishing Company,Inc.

Ernawati, Pita. 2007. Analisis Faktor-Faktor Yang Mempengaruhi Kepuasan Kerja Karyawan (Studi Pada Karyawan Bagian Non Marketing PT Ford Motor Indonesia). Tesis. Magister Manajemen. Universitas Indonesia.

Flippo, Edwin B, 2007, Manajemen Personalia, Terjemahan, Erlangga, Jakarta.

Gibson, Ivan Cevich, Donnelly. 2006. Organisasi, Perilaku Struktur, Proses. Edisi Kedelapan. Binarupa Aksara. Jakarta. 
Greenberg J. and Baron R.A. 2003. Behavior in Organization. Fourth Edition. Allyn and BaconBoston. USA.

Handoko, T. Hani. 2008. Manajemen Personalia Dan Sumber Daya Manusia. Edisi Kedua. BPFE. Yogyakarta.

Harris, Michael. 2007. Human Resource Management Apractical Approach. The Dryden Press. USA.

Hasibuan, Malayu SP. 2005. Manajemen Sumber Daya Manusia. Cetakan Kedelapan. Gunung Agung. Jakarta.

Heidjrahman, Ranupandojo dan Suad Husnan, 2004, Manajemen Personalia, BPFE, Yogyakarta.

Husnan, Suad. Heidjrachman P. 2004. Manajemen Personalia. Edisi Keempat. BPFE. Yogyakarta.

Ibrahim, Adam. 2008. Perilaku Organisasi. Sinar Baru. Bandung.

Kartono, Kartini. 2004. Psikologi Sosial Untuk Manajemen, Perusahaan dan Industri. Edisi Ketiga. PT. Raja Grafindo Persada. Jakarta.

Kouzes, James M, Barry Z Posner. 2007. Kredibilitas. Terjemahan Anton Adiariyoto. Profesinal Books. Jakarta.

Kuncoro, Tri. 2014. Analisis Faktor - Faktor Yang Berpengaruh Terhadap Kepuasan Kerja Dokter Di Rumah Sakit Jiwa Daerah Dr. Rm. Soedjarwadi Provinsi Jawa Tengah. Tesis. Program Studi Manajemen Rumah Sakit. Universitas Muhammadiyah Yogyakarta

Mangkunegara, A.A. Anwar Prabu. 2003. Psikologi Perusahaan. PT. Trigenda Karya. Bandung.

Martoyo, Susilo. 2005. Manajemen Sumber Daya Manusia. BPFE. Yogyakarta.

Nawawi, Hadari, 2003, Manajemen Sumberdaya Manusia, Gajahmada University Press, Yogyakarta.

Nitisemito S. Alex. 2003. Manajemen Personalia. Edisi Ketiga. Ghalia Indonesia. Jakarta.

Nurgiyantoro, Burhan. 2005. Statistik Terapan: Untuk Penelitian Ilmu-Ilmu Sosial. Cetakan Pertama. Penerbit Gadjah Mada University Press. Yogyakarta.

Pamudji S., 2005, Kepemimpinan Pemerintahan di Indonesia. Edisi I Cetakan Ketujuh, Bumi Aksara, Jakarta.

Robbins, Stephen P. 2006. Perilaku Organisasi : Konsep Kontroversi Aplikasi. Jilid Pertama. Alih Bahasa Pujaatmaku dan Hadyana. Prenhallindo. Jakarta. 
Sabardi, Agus. 2007. Pengantar Manajemen. UPP. AMP. YKPN. Yogyakatra.

Santoso, Singgih. 2002. Mengolah Data Statistik Secara Profesional. Cetakan Ketiga. Penerbit PT. Elex Media Komputindo. Jakarta.

Schein, Edgar H. 2001. Psikologi Organisasi. PPM-UGM. Yogyakarta.

Shobaruddin, M. (Trans). Kenneth N. Wexley dan Gary A. Yulk. 2002. Organizatinal Behavior and Personnel Psychology. Cetakan Kedua. PT. Rineka Cipta. Jakarta.

Shofia, Amin. 1995. Pengaruh Faktor-Faktor Kepuasan Kerja Terhadap Keberhasilan Kerja Ajun Penyuluh Keluarga Berencana Madya di Propinsi Jambi. Tesis. Program Pascasarjana Universitas Airlangga. Tidak Diterbitkan.

Siagian, Sondang P. 2002. Manajemen Sumber Daya Manusia. Edisi Kesatu. Cetakan Kesatu. Bumi Aksara. Jakarta.

Spector, Paul E. 1997. Job Satisfaction, Application, Assessment, Causes and Consequencer. Sage Publication Inc. California.

Sugiyono. 2010. Metode Penelitian Administrasi. Cetakan pertama. CV. Alfabeta. Bandung.

Werther, William B. Jr. and Keith Davis. 2006. Human Resourtces and Personnel Management. Fifth Edition. McGraw-Hill Inc. USA.

Wexley, K.N dan Yulk, G.A. 1997. Organizational Behavior and Personal Psychology. Richard D. Irwin : Home Wood. Illinois.

Yulianto, Anton Eko. 1996. Analisis Beberapa variabel yang Mempengaruhi Kepuasan Kerja Sumberdaya Manusia, Suatu Studi Kasus BUMN PT. Cipta Niaga Surabaya. Tesis. Program Pascasarjana Universitas Airlangga Surabaya. Tidak Diterbitkan. 